\title{
Toward a More Clinically Valid Approach to Therapy Research
}

\author{
Marvin R. Goldfried \\ Department of Psychology State University of New York at Stony Brook \\ Barry E. Wolfe
}

American Schools of Professional Psychology, Virginia Campus

ABSTRACT

Despite the advances in psychotherapy outcome research, findings are limited because they do not fully generalize to the way therapy is conducted in the real world. Research's clinical validity has been compromised by the medicalization of outcome research, use of random assignment of clients without regard to appropriateness of treatment, fixed number of therapy sessions, nature of the therapy manuals, and use of theoretically pure therapies. The field needs to foster a more productive collaboration between clinician and researcher; study theoretically integrated interventions; use process research findings to improve therapy manuals; make greater use of replicated clinical case studies; focus on less heterogeneous, dimensionalized clinical problems; and find a better way of disseminating research findings to the practicing clinician.

Work on this article was supported in part by National Institute of Mental Health Grant 40196. Correspondence may be addressed to Marvin R. Goldfried, Department of Psychology, State University of New York, Stony Brook, New York, 11794-2500.

Electronic mail may be sent to mgoldfried@ccmail.sunysb.edu

Received: Received March 4, 1997

Accepted: Accepted June 3, 1997

From time to time, psychotherapy researchers have complained that their findings have not sufficiently impacted on the practitioner or policymaker. We have carped that our voices have not been heard in high councils and that our wisdom unrecognized and unrequited by government decision makers. I regret to inform you that those idyllic days are now gone. We can no longer be confident that our papers will be read only by fellow researchers. Policymakers are reading our reports, and the clinicians are listening. ( Parloff, 1979, p. 296) 
We have been asked to comment on the current state-of-the-art for conducting psychotherapy outcome research and conclusions about those intervention procedures that have been empirically supported. In doing so, we find ourselves in a strange position. Having spent our professional lifetimes in the pursuit of ways to provide an empirical foundation for our treatment procedures, we find it awkward to be taking a somewhat critical view of our research efforts to date. Although we wholeheartedly acknowledge that the field has compiled an impressive array of research findings that can inform clinical practice, we will address ourselves primarily to some of the shortcomings of our current research paradigm and suggest ways to overcome these limitations.

The current attempt to arrive at a consensus on which therapies have been empirically "validated" or "supported" has aroused considerable controversy. This issue was hotly debated at recent meetings of the Society for Psychotherapy Research (SPR) and the Society for the Exploration of Psychotherapy Integration (SEPI). No less than five other journals that we know of have devoted space to deal with this topic, including the American Psychologist, Clinical Psychology: Science and Practice, Journal of Psychotherapy Integration, Psychotherapy Research, and Psychotherapy.

In this issue, the guidelines presented by Chambless and Hollon (1998) for determining which therapies have received empirical support and the specific articles by Baucom, Shoham, Meuser, Daiuto, and Stickle (1998), Compas, Haaga, Keefe, Leitenberg, and Williams (1998), DeRubeis and Crits-Christoph (1998), and Kazdin and Weisz (1998) evaluating the research evidence for the treatment of various clinical problems are indeed comprehensive and impressive. The contributions are carefully thought out, attending to the methodological issues associated with current standards for psychotherapy research, and offering us a clear overview of our research findings to date.

There indeed is a methodological elegance to our current approach to psychotherapy outcome research. We certainly admire an elegantly designed study as much as anyone and have spent countless hours developing and evaluating treatment studies that have impeccable internal validity. Indeed, we have found it all too easy to get caught up in a research paradigm and lose sight of its ecological shortcomings. And although we agree with Chambless and Hollon (1998) that inferences can more confidently be drawn from controlled research than from surveys involving correlational findings ("Mental health: Does therapy help?" 1995; Seligman, 1995), we maintain that such controlled research is severely limited if it fails to meet the more basic criterion of having clinical validity.

The question of whether our research designs have external or clinical validity is no longer an academic issue, especially in light of current pressures for the accountability of psychotherapy. This phenomenon is worldwide and is dramatically seen in the United States, where insurance companies are starting to become interested in the effectiveness of our intervention methods. To be sure, we as psychotherapy researchers have long expressed concern about clinical colleagues who continue to practice in ways that may be at odds with research findings. The gap between research and practice is certainly not new, and the need to close it should be goal of both clinicians and researchers.

As anyone who has been involved in the design or implementation of psychotherapy outcome research 
well knows, there are numerous methodological, practical, and financial constraints that limit what may be done in our therapy protocols. Thus, we randomly assign Diagnostic and Statistical Manual of Mental Disorders ( DSM ) diagnosed patients to treatments and predetermine how many sessions will be needed to bring about clinically meaningful change. Of necessity, this all contributes to the gap between research and the way therapy is practiced in the real world, a point acknowledged by Calhoun, Moras, Pilkonis, and Rehm (1998), DeRubeis and Crits-Christoph (1998), and Kazdin and Weisz (1998). Should insurance companies begin to use information on empirically validated or supported therapies to certify the type-and length-of interventions they deem reasonable, the research-practice gap may be closed for us by others. Our concern is that the methodological and other constraints that have shaped our research designs will translate into clinical constraints for the practicing therapist, with serious consequences for practitioners and their patients.

We begin with a brief overview of the changing methodology in psychotherapy outcome research over the past five decades and then go on to voice our concerns about the medicalization of outcome research, the use of random assignment of clients to treatment conditions, the use of a fixed number of sessions, the nature of the therapy manuals that are used, and the use of theoretically pure therapies. Toward the goal of reducing the essential tension between clinician and researcher and making our research more clinically valid, we suggest that steps be taken to foster a more productive collaboration between clinician and researcher, study theoretically integrated interventions, use process research findings to improve our therapy manuals, make greater use of replicated clinical case studies, focus on less heterogenous, dimensionalized clinical problems, and find a better way of disseminating our research findings to the practicing clinician.

\section{Validity and Utility of Psychotherapy Outcome Research}

Close to one half century ago, Snyder (1950) reviewed the findings of what at the time was the state-ofthe-art in psychotherapy outcome research. These early studies, which we have referred to as Generation I research ( Goldfried \& Wolfe, 1996), sought to answer the question: Is psychotherapy effective in producing personality change? This global question did little to specify either the nature of the clinical problems being studied or the type of intervention procedures used.

Advances in the research paradigm began in the 1960s, with the advent of behavior therapy. Rather than address the question of whether psychotherapy works, Generation II outcome research received its impetus from behavior therapy researchers, who began to compare different methods for treating specific target problems (e.g., phobias and public speaking anxiety). Given the fact that behavior therapy grew out of a research context, it is not surprising that numerous methodological advances were made over the earlier paradigm. The therapy manual was invented, patients were randomly assigned to treatment conditions, and other methodological considerations were incorporated into this generation of research.

Generation III can be dated as beginning in the 1980s, due in large part to the NIMH Treatment of Depression Collaborative Research Program ( Elkin, Parloff, Hadley, \& Autry, 1985). In this third generation, there was a definite shift toward a medical model. Outcome research became clinical trials, 
the term used for drug studies, and target problems were replaced by DSM diagnoses. There was also a move toward using clinical populations, more detailed therapy manuals, and greater care in determining that therapists adhered to the treatment protocol. The methodological standards described by Chambless and Hollon (1998) and the reviews by Baucom et al. (1998), Compas et al. (1998), DeRubeis and CritsChristoph (1998), and Kazdin and Weisz (1998) are in the best tradition of this current generation of studies.

As we indicated earlier, however, no amount of concern for methodological rigor-internal validity-can substitute for a research paradigm that will allow us to generalize to clinical reality-external validity. This is clearly a concern that is held by other empirically minded clinical psychologists (e.g., Bergin, 1997 ; Calhoun et al., 1998 ; Kazdin \& Weisz, 1998 ; Garfield, 1996; Seligman, 1995 ; Strupp \& Anderson, 1997 ). In their introduction to a special section of the Journal of Consulting and Clinical Psychology on "transporting" therapy research findings to the clinical setting, Hoagwood, Hibbs, Brent, and Jensen (1995) characterized efficacy research as focusing primarily on internal validity. The challange for effectiveness research, they noted, is to add the component of external validity while still preserving internal validity.

The issue of maintaining a balance between internal and external validity has been a concern of longstanding to experimental methodologists ( Bannister \& Fransella, 1971; Brunswik, 1952; Fisher, 1947 ). Brunswik made the important distinction some years ago when he referred to systematic designs as those that have as their primary consideration tight experimental controls, as compared with representative designs that more accurately sample the universe to which one wishes to generalize. Only the latter, suggested Brunswik, have ecological validity. This same point was made by none other than R. A. Fisher, who observed,

The exact standardization of experimental conditions, which is often thoughtlessly advocated as a panacea, always carries with it the real disadvantage that a highly standardized experiment supplies direct information only in respect of the narrow range of conditions by standardization. Standardization, therefore, weakens rather than strengthens our ground for inferring a like result. (p. 97)

Finally, in commenting on the tendency for design considerations to override one's attention to the phenomena being investigated, Bannister and Fransella wryly observed that such studies "were born out of the literature and, no doubt, will be buried in it" (p. 193).

Our major concerns about Generation III psychotherapy outcome research methodology reflected in this special issue of the Journal of Consulting and Clinical Psychology consist of the following: (a) Its use of the medical model, (b) the random assignment of patients to treatments, (c) the fixed number of sessions, (d) the therapy manuals that have been used, and (e) its use of theoretically pure therapies. 
During the 1970s, the National Institute of Mental Health (NIMH) and its parent organization, the Alcohol, Drug Abuse, and Mental Health Administration (ADAMHA) began to assume greater responsibility as third-party mediators between mental health providers and consumers. Part of this task involved responding to congressional concerns regarding the mounting expenditures for mental health care, especially through Medicare and Medicaid. Congress was then-as now-afflicted with a severe case of anticipatory anxiety regarding the increasingly expensive costs for providing mental health care. These concerns heightened the need to collect clear, replicable data on the efficacy of psychotherapy. With the increasing influence of psychiatry at the NIMH and the fact that drug therapies were providing convincing evidence of symptomatic benefits for a number of specific disorders, the clinical trial eventually was ratified as the standard means by which the efficacy of any treatment would be evaluated. A decision was made by the NIMH, the leading source of research funds for psychotherapy research, that the same standards used in pharmacotherapy research would be applied to the evaluation of the psychotherapies. This meant that standardized psychosocial treatments needed to be evaluated in terms of their efficacy in reducing the symptoms of a specific DSM -defined mental disorder.

In fact, the original purpose of the Treatment of Depression Collaborative Research Program (TDCRP) was to test the feasibility of the clinical trial research design for the evaluation of standardized psychotherapies. The influence of the TDCRP on the conduct of NIMH-funded psychotherapy research was profound. Among other effects, it cemented the requirement that any treatment study must include manualized therapies and $D S M$-defined disorders in order to be eligible for a research grant from the NIMH. All the research rigor that allegedly characterized efficacy studies of pharmacotherapeutic agents was now to be included in corresponding studies of standardized psychosocial treatments.

Also relevant is the fact that, somewhat earlier, a decision had been made by the director of the Intramural Research Program of the NIMH to tilt toward the biological perspective on mental illness. In an official policy statement published around 1970, the director had argued that the future of research on mental illness rested with progress in the biological understanding and treatment of these disorders. It was believed that this step was necessary if the field of treatment research was ever to achieve scientific respectability and, not insignificantly, if Congress were to be persuaded that it is necessary to continue appropriating funds for mental health research (M. B. Parloff, personal communication, 1997). All of these factors influenced the increasing medicalization of psychotherapy outcome research.

There have been both positive and negative consequences of this trend. We agree with Chambless and Hollon (1998) that the use of DSM diagnoses in our outcome studies has the advantage of providing the field with consistency from one study to another and a link to the psychopathology literature. In the final analysis, however, we believe that it very well may have been a move in the wrong direction. The focus on DSM diagnostic disorders, as compared with the target problems studies in Generation II studies (e.g., examination anxiety and unassertiveness) constrains how we think about, and the kinds of questions we ask about, clinical problems.

For example, we make attempts at understanding so called comorbidity between anxiety and depression, rather than considering the possibility that anxiety may inhibit competent functioning that results in a 
diminished view of self and a dysphoric mood. Thus, thinking in terms of two concurrent disorders does little to help us uncover the functional cause-effect relationship between clinical problems. With diagnostic categories being the focus of our outcome research, little concern is given to the unique determinants/dynamics that may be relevant to our interventions (cf. Clarkin \& Kendall, 1992).

Moreover, the disease model moves us in the direction of overemphasizing symptom reduction as the primary outcome measure, a tendency Chambless and Hollon (1998) caution us against.

Even as a means of conducting basic research on psychopathology, it has been suggested that "the current state of psychopathologic nosology and diagnosis resembles that of medicine a century ago" ( Millon, 1991, p. 245). It has also been argued that our DSM system represents a serious roadblock to progress, as the belief in a common cause for inclusion in a diagnostic category "would appear to be at best an injudicious hope and at worst a seriously misleading encouragement to the waste of precious research resources in pursuit of what appear to be largely chimerical objectives" ( Carson, 1997, p. 106). In short, there is reason to seriously question whether the DSM system for categorizing clinical problems, a pivotal focus in our outcome research, fruitfully carves nature at its joints.

\section{Random Assignment to Treatment}

One of the major advances that Generation II research made over Generation I methodology was the practice of randomly assigning patients to the different therapy conditions. The objective here is obvious, namely that of eliminating any potential sources of bias and internal confounding that might exist in the selective assignment of participants to different treatment conditions. Thus, in order to have an accurate test of the relative effectiveness of two treatment procedures, it is essential that patients being seen in each of the conditions be comparable in regard to certain crucial variables, such as duration of problem and severity.

We have no problems with the use of random assignment per se. However, problems arise by virtue of the heterogeneity of some of the diagnostic categories studied in our outcome research. Take, for example, the clinical problem of depression. Our clinical experience and that of our colleagues suggests that some individuals are depressed because they have an unrealistically self-critical view of themselves, whereas others may be depressed because of interpersonal issues, in which they unwittingly elicit persistent negative reactions from significant others. With random assignment, we can assume that individuals representing these two particular subtypes will be comparably represented in different treatment conditions. If the study involves the comparison of cognitive therapy with interpersonal therapy for the treatment of depression, it becomes clear that random assignment can only serve to undermine the likelihood that one intervention procedure will prove more effective than the other. Some patients will be appropriately matched to the intervention (i.e., cognitive therapy for self-critical patients and interpersonal therapy for those with relational problems), whereas others will not. Not only does this methodological practice make little clinical sense, but because it fosters within-group variance, it often ends up telling us little empirically about the therapeutic efficacy of different treatments for given clinical problems. 
There are many other clinically useful distinctions that may be made within depression, because of, no doubt, the heterogeneity of the diagnostic category. However, the attempt to deal with this heterogeneity by random assignment can shed light only on which intervention is best suited for which type of patient if the design includes matched and mismatched subgroups. Some hints as to the potential patient moderators of change may be gotten by post hoc analyses with clinically relevant pretest patient characteristics, provided they were included in the research design. Without very large numbers in the different treatment conditions, however, there may be insufficient statistical power to reveal the interaction of patient characteristics with treatment procedure.

\section{Fixed Number of Sessions}

Another methodological advance made in Generation II research was the practice of equating the number of therapy sessions received by participants in different treatment conditions. As with the use of random assignment, this methodological procedure attempts to ensure that one intervention does not receive unfair advantage over another, as it clearly would if it involved more therapeutic contact.

Although the field has not yet reached the point at which we can determine in advance exactly how many sessions are required to successfully treat a given clinical problem, such decisions nonetheless must be made by the outcome researcher. More often than not, practical and financial matters come into play, and there always exists the danger that the length of the intervention may be insufficient to adequately deal with the clinical problem at hand. This arbitrary abbreviation of duration of treatment might result in some of the phenomena described by Chambless and Hollon (1998) when they note that certain interventions may have a delayed treatment effect, not showing improvement until well after treatment has been completed. The brief number of sessions often used in our current research may also contribute to the point they make about a methodological difficulty in conducting follow-up evaluations; some patients seek out additional treatment after they complete their participation in the research protocol.

\section{Use of Treatment Manuals}

An essential feature in the current state-of-the-art in psychotherapy outcome research is the use of treatment manuals. This began in Generation II research and has been refined still further in more recent years. Clearly, its primary function is to ensure that the intervention procedures being studied are adhered to by the therapists and that they involve distinctly different interventions. Moreover, the use of treatment manuals enable the more faithful replication of outcome studies, a practice that is essential in determining the effectiveness of psychotherapy.

However appealing the idea of treatment manuals may be, there nonetheless are limitations. As cautioned some years ago by Kendall and Hollon (1983), following a manual does not necessarily guarantee the quality of therapy provided. More recently, Garfield (1996) has suggested that whatever methodological advantages may exist with treatment manuals, they also limit external validity. Because of the complexities of clinical practice and the need to tailor one's intervention to the particular patient, most therapists do not do therapy "by the book," a point that Calhoun et al. (1998) underscore when they 
consider the issue of clinical training.

There is some recent evidence to suggest that therapy manuals, used in the context of outcome research, may at times constrain clinical practice. For example, Henry, Strupp, Butler, Schacht, and Binder (1993) found that overly conscientious adherence to the treatment manual in the Vanderbilt II study led shortterm psychodynamic therapists to achieve less favorable results. A comparable finding is reported by Castonguay, Goldfried, Wiser, Raue, and Hayes (1996) with cognitive therapists, whereby strict adherence to the manual was associated with difficulties in the therapeutic alliance.

\section{Use of Theoretically Pure Therapies}

The vast majority of the research reviewed by Baucom et al., (1998), Compas et al. (1998), DeRubeis and Crits-Christoph (1998), and Kazdin and Weisz (1998) has involved comparison of theoretically pure interventions. Given the fact that few therapists administer theoretically pure interventions in clinical practice ( Norcross \& Goldfried, 1992 ), there is somewhat of an anachronistic character to our outcome research. To be sure, the conclusion by practicing clinicians that the integration of different forms of treatment enhances their effectiveness is based on clinical impression. Nonetheless, it is the impression of a large number of practitioners that making use of contributions from different theoretical approaches increases clinical effectiveness ( Norcross \& Goldfried, 1992; Stricker \& Gold, 1993 ). Although this inconsistency between research and practice may seem strange, it nonetheless is not new. Parloff (1979) noted it some years ago when he observed that "there appears to be an inverse relationship between the frequency with which a treatment form is actually used by practitioners and the frequency with which that treatment has been studied" (p. 304). Close to two decades later, this discrepancy continues to exist.

\section{Research and Practice: An Essential Tension}

There is a long history of mutual antagonism between clinician and researcher. Although both are presumably dedicated to the development and implementation of effective intervention procedures, psychotherapy researchers and practicing clinicians live in different professional worlds. Between the two of us, we have spent more than 50 years functioning within both of these worlds and have been dismayed with the ongoing disparity and conflict we have observed between our clinical and empirical colleagues ( Goldfried \& Wolfe, 1996 ).

The tension between psychotherapy researcher and practitioner at times takes a subtle form. Other times, it is more blatant, as when one hears academic colleagues refer to graduates of clinical training programs as having been "lost to clinical work." Clinicians have similarly stereotyped academicians, as in the case of one clinician who concluded that psychotherapy research is possible only if one views it "in the mechanical way that is so fashionable among many of our colleagues who are too frightened and too inept to establish an interpersonal relationship of a therapeutic variety with a patient" ( Lehrer, 1981, $p$. 42). 
For the most part, reviews of psychotherapy efficacy, including those included in this issue, tend to emphasize the results of controlled studies at the expense of clinical experience and skill. Chambless and Hollon (1998) note that our research designs have only recently taken into account the competency with which therapists implement a given intervention. The fact that we have only recently begun to seriously consider the competency of the therapists within our research designs reflects the fact that we, as psychotherapy researchers, have been all too caught up in methodology and not good clinical sense. After all, it is unlikely that we as therapy researchers would ignore a clinician's competency and personal characteristics when referring a friend or relative to a therapist.

A frequent source of irritation that researchers express toward practicing clinicians is that they are not good consumers of our research findings. What we all too rarely consider is the possibility that this might have something to do with our product and how it is packaged. Our group designs may have relatively little to say to the practicing clinician, and the way we present research findings is typically in the form to be consumed by other researchers, not by the practicing clinician. The issue of whether our research is useful to practicing clinicians has similarly been questioned by Persons and Silberschatz (1998).

In our move to arrive at a consensus regarding which interventions have been supported empirically, we may have inadvertently further alienated our clinical colleagues. A case in point is the recent article by Fensterheim and Raw (1996), two practicing clinicians who lament how little relevance the psychotherapy outcome research has for routine clinical practice. We personally know that these clinicians have had a long-standing interest in empirical findings and have conscientiously kept up with the research literature. Despite this, they reported feeling betrayed by the attempts of psychotherapy researchers to delineate practice guidelines on the basis of research findings that underemphasize clinical flexibility. In commenting on the pressures for implementing therapy along the lines dictated by research findings, Fensterheim and Raw voiced their concern about

who should make the decision about how much flexibility is allowable, of how large should be the Procrustean bed. We doubt that it will be the practicing therapist who does so. So, once again, the standards and methods of clinical therapy will be set by those who do the least amount of clinical practice. (pp. 169-170)

\section{Future Directions}

The challenge of managed health care and biological psychiatry has forced the field of psychotherapy to confront the issue of accountability in a way that it has never needed to before. As psychotherapy researchers, we can no longer confine ourselves to the academic issues of therapeutic efficacy when there are very real life consequences associated with the direction we take with our research methodology. This leads us to confront a very basic question: What is the purpose of outcome research if not to inform the practicing clinician? The long-neglected issue of external validity must now be dealt with in new and creative ways. 
In his critique about current outcome methodology, Seligman (1995) has presented the results of the Consumer Reports survey as a research methodology having better external validity. Although we are not as critical of this methodology as are some of our colleagues, nonetheless we do not believe that it can replace controlled outcome research. As we have argued elsewhere (Goldfried \& Wolfe, 1996 ), however, we firmly believe that the field needs to move on to a fourth generation of research. The exact form of Generation IV is as yet unclear. Still, there are some general directions that need to be taken, including the collaboration between researcher and practitioner; the need to study theoretically integrated treatments; the use of process research findings to improve our therapy manuals; the use of clinical case replications; the need to focus on less heterogeneous, dimensionalized clinical problems; and finding a better way of disseminating our research findings to the practicing clinician.

\section{Clinician-Researcher Collaboration}

There has been a growing recognition of the need to forge a liaison between clinician and researcher in the design and implementation of outcome research ( Beutler, Kim, Davison, Karno, \& Fisher, 1996 ; Borkovec \& Miranda, 1996 ; Campbell, 1996; Drozd \& Goldfried, 1996; Goldfried \& Wolfe, 1996; Hayes, 1981 ; Sobell, 1996 ; Wiens, Brazil, Fuller, \& Solomon, 1995 ). The call for such a collaboration was made several years ago by Hayes (1981), who concluded an article on the use of single-case methodology with the following:

Practicing clinicians are essential to the development of our knowledge base in clinical psychology. ... Indeed, the resources needed to repeatedly replicate single-case experimentation are available only by including practicing clinicians. If combined, these needs, abilities, and resources could create a true revolution in clinical psychology. The question is, will they be? (p. 209)

Little in the way of collaboration between researcher and clinician has been implemented since Hayes (1981) highlighted this issue more than 15 years ago. However, in very recent years, matters have changed, and efforts are beginning to be made in this direction (e.g., Borkovec \& Miranda, 1996; Sobell, $1996)$. Given the need to make outcome research more clinically relevant, as well as the availability of naturally existing clinical communities (e.g., group practices, health maintenance organizations, state psychological associations, and practicing clinicians who have graduated from research-oriented academic programs), it is only a matter of time before such collaborative efforts become incorporated into the fourth generation of outcome research.

\section{Studying Integrated Treatments}

It has become increasingly clear that we need to treat more than just symptoms of a given clinical problem and that no existing therapy orientation is comprehensively effective for any disorder. Increasingly, therapists are combining therapies from different orientations, and the promising clinical results of such endeavors have moved a growing number of clinicians and researchers to ponder the 
development of therapies that integrate clinical strategies devised by different therapy orientations. Already a substantial number of approaches to the systematic development of an integrative therapy have been delineated in two recently published handbooks of psychotherapy integration ( Norcross \& Goldfried, 1992 ; Stricker \& Gold, 1993 ). Although most of these systems were developed from clinical observation, very few have been empirically tested-perhaps awaiting a therapy manual that would be the prerequisite for obtaining research funding from the NIMH. In light of the clinical promise of many of these integrative therapies, there is a crying need for outcome research to confirm the effectiveness of these interventions.

Once the effectiveness of integrative therapies have been empirically established, it will be necessary to determine the appropriate sequencing of its active treatment elements. Clinical rationales must be articulated for selecting and sequencing treatment, and the evolving decision rules must be specified ( Wolfe \& Goldfried, 1988). A second approach to the development of an integrative treatment is through the conduct of psychotherapy process research to identify more precisely the mechanisms of therapeutic change. Again, once these elements of an effective treatment have been identified, decision rules for their sequencing will need to be developed and tested. Despite the difficulties posed by these challenges, we believe that the development and evaluations of integrative therapies may well result in more comprehensively effective treatments than have been investigated to date.

\section{Designing Better Therapy Manuals}

As we have suggested earlier, many of our current therapy manuals do not provide enough flexibility to the therapist for handling the problems and issues that may arise within an individual case context. We agree with Calhoun et al. (1998) that what is often absent in many manuals are therapeutic guidelines for what to do when confronted with in-session dilemmas. Work is currently underway to develop more clinically flexible manuals, including guidelines for what to do when one encounters problematic clinical situations (P. C. Kendall, personal communication, April 17, 1997).

For example, what is the therapist to do when he or she encounters a rupture in the therapeutic alliance during the process of delivering a given intervention procedure? It is here that the findings of psychotherapy process research can be put to important use in designing our treatment manuals (e.g., Safran \& Muran, 1995). When one is addressing the question of what therapists do under different conditions that help or hinder therapeutic progress, process findings can be used as valuable guidelines for the practicing clinician.

\section{Clinical Case Replications}

With the movement from Generation II to Generation III outcome research, there appears to have been a decrease in emphasis on single-case research. Provided that one takes into account methodological considerations associated with internal validity ( Kazdin, 1981 ), the results of such research, particularly if it involves the compilation of comparable cases treated in similar ways, can have much to say to the practicing clinician. 
Within recent years, there has been a renewed interest in single-case methodology ( Jones, 1993 ). In an attempt to make research findings more relevant to the practicing clinician, Howard, Moras, Brill, Martinovich, and Lutz (1996) proposed a method for individualized case profiling, based on which phase of the change process is appropriate for any given client. Depending upon whether the therapeutic goal is (a) remoralization, (b) symptom reduction, or (c) learning new ways for dealing with life events, the intervention procedures and measures of outcome will vary. Thus, the individual case methodology is designed to maximally tailor the intervention to the particular clinical case, thereby enhancing external validity.

\section{Need to Focus on Less Heterogeneous and Dimensionalized Clinical Problems}

In critiquing the use of random assignment in our current research methodology, we indicated earlier that the problem rested primarily in the heterogeneous, categorical nature of our DSM classification system that is inherent to our current generation of outcome research. The limitations of this categorical system are noted by Calhoun et al. (1998) and have been underscored in a recent conference sponsored by the American Psychological Association on the development of a core assessment battery to be used in outcome research, in which the importance of using measures of more focal and dimensionalized symptoms and characteristics (e.g., worry) was underscored ( Strupp, Horowitz, \& Lambert, 1997 ).

In addition to a research methodology that emphasizes greater homogeneity of clinical problems, there is also a need to help match the therapy interventions with relevant patient characteristics. There is already a substantial literature in progress on matching treatment intervention to client needs, which has grown in complexity and sophistication during the last two decades. Three broad treatment dimensions have been proposed: (a) personal compatability, (b) treatment technique, and (c) patient stage of change ( Beutler, 1983 ; Prochaska \& DiClemente, 1992 ). Investigators are now attempting to match different interventions and different interpersonal stances, or relational styles, with different types of clients. This has led in practice to the development of several systems of prescriptive psychotherapy, such as Norcross's (1994) prescriptive eclectic therapy, Beutler's (1983) systematic eclectic psychotherapy, and the systematic treatment selection of Beutler and Clarkin (1990). Norcross and Beutler (1997) have suggested four client markers that serve as criteria for matching different styles with different clients: (a) patient expectancies, (b) stage of change, (c) patient's resistance potential, and (d) patient's personality and coping style.

This research direction gives promise of increasing the usefulness of the findings of group research design for clinical practice. Just as single-case methodology can uniquely design an intervention for a given case, so is it possible to alter our group design methodology so that patients are assigned to interventions that best match their clinical needs.

\section{Dissemination of Findings}


Most psychotherapy research articles and reviews of the literature are written for other researchers. In order to evaluate the adequacy of the design and findings, certain information clearly needs to be presented in our research reports. Moreover, given the advances as we have made methodologically, much of what is described includes technical research language (e.g., "end-state functioning," "treatment fidelity," and "effect size"). Although this information and language is crucial for communicating our findings to other researchers, it is less important-and indeed is often incomprehensible-to the practicing clinician.

It is unrealistic to expect that the practicing clinician will be in the position to evaluate the methodological adequacy of our research findings; nor are they interested in doing so. Their primary concern-which is perhaps greater than ever before-is learning about what works. Although it may be difficult to do so, researchers need to provide the clinician with a summary of intervention findings for different clinical problems in such a way that is both comprehensible and useful. In our experience with editing the journal In Session: Psychotherapy in Practice, researchers must make special efforts to communicate to the practicing clinician. 1 In doing so, however, it is possible to provide jargon-free overviews of what we know about clinical problems and their treatment.

Recognizing the limited external validity of drug therapy clinical trials, Frances, Kahn, Carpenter, Ross, and Docherty (1996) have proposed an ingenious procedure for bringing clinical experience and research findings together in establishing and communicating guidelines for practice. Clinical researchers who are experts in the treatment of particular disorders (e.g., schizophrenia and bipolar disorder) rate the extent to which various drug treatments would be appropriate for a given disorder under varying clinical circumstances. In addition to these research experts, a sample of clinical experts who work with the particular patient population similarly rate the appropriateness of various drug treatments. The resulting guidelines are thus based on a consensus of well-informed clinical and research perspectives. We suggest that this approach has great promise in determining which empirically supported psychosocial procedures may be appropriate under varying clinical conditions.

\section{Conclusion}

Being at a critical crossroads, we need careful thought and ongoing dialogue to help guide us in the future directions we take. We applaud the recommendation of the Task Force on Promotion and Dissemination of Psychological Procedures (1995), which urges clinician-researcher round-table discussions of these very important issues. This need to close the unfortunate gap between researcher and practitioner as a way of advancing the field has been called for by others in the past. As indicated by Goldfried and Padawer (1982),

If one views the split between clinicians and researchers from outside the entire system, it becomes more evident that both groups are deluding themselves in thinking that they alone will advance the field. Stated more positively, it is perhaps more productive to conclude that both groups very much need each other. The experience and wisdom of the practicing 
clinician cannot be overlooked. But because these observations are often not clearly articulated, may be unsystematic or at times idiosyncratic, and are typically kept informal, it is less likely that these insights can add to a reliable body of knowledge. The growing methodological sophistication of the researcher, on the other hand, is in need of significant and ecologically valid subject material. Our knowledge about what works in therapy must be rooted in clinical observations, but it must also have empirical verification. For the researcher and clinician to ignore the contributions that each has to make is to perpetuate a system in which no one wins. (p. 33)

Both researchers and clinicians, working collaboratively, need to become more actively involved in the issue of how research can intelligently inform practice and how practice can intelligently inform research. There is a slow but growing movement to involve the practicing clinician in the design and implementation of psychotherapy research. It is clearly more than a conceptual or methodological issue; the very future of psychotherapy practice may depend on it.

\section{References}

Bannister, D. \& Fransella, F. (1971). Inquiring man. (Middlesex, England: Penguin) Baucom, D. H., Shoham, V., Meuser, K. T., Daiuto, A. D. \& Stickle, T. R. (1998). Empirically supported couple and family interventions for marital distress and adult mental health problems.( Journal of Consulting and Clinical Psychology, 66, 53-88.)

Bergin, A. E. (1997). Neglect of the therapist and the human dimensions of change: A commentary.( Clinical Psychology: Science and Practice, 4, 83-89.)

Beutler, L. E. (1983). Eclectic psychotherapy: A systematic approach. (Elmsford, NY: Pergamon) Beutler, L. E. \& Clarkin, J. F. (1990). Systematic treatment selection: Toward targeted therapeutic interventions. (New York: Brunner/Mazel)

Beutler, L. E., Kim, E. J., Davison, E., Karno, M. \& Fisher, D. (1996). Research contributions to improving managed health care outcomes.( Psychotherapy, 33, 197-206.)

Borkovec, T. D. \& Miranda, J. (1996). Between-group psychotherapy outcome research and basic science.( Psychotherapy and Rehabilitation Research Bulletin, 5, 14-20.)

Brunswik, E. (1952). The conceptual framework of psychology. (Chicago: University of Chicago Press)

Calhoun, K. S., Moras, K., Pilkonis, P. \& Rehm, L. P. (1998). Empirically supported treatments: Implications for training.( Journal of Consulting and Clinical Psychology, 66, 151-162.)

Campbell, L. F. (1996). The treatment outcome pursuit: A mandate for the clinical and researcher working alliance.( Psychotherapy, 33, 190-196.)

Carson, R. C. (1997). Costly compromises: A critique of the Diagnostic and Statistical Manual of Mental Disorders. (In S. Fisher \& R. Greenberg (Eds.), From placebo to panacea: Putting psychiatric drugs to the test (pp. 98-112). New York: Wiley.)

Castonguay, L. G., Goldfried, M. R., Wiser, S. L., Raue, P. J. \& Hayes, A. M. (1996). Predicting the effect of cognitive therapy for depression: A study of unique and common factors.( Journal of Consulting and Clinical Psychology, 64, 497-504.)

Chambless, D. L. \& Hollon, S. D. (1998). Defining empirically supported therapies.( Journal of 
Consulting and Clinical Psychology, 66, 7-18.)

Clarkin, J. R. \& Kendall, P. C. (1992). Comorbidity and treatment planning: Summary and future directions.( Journal of Consulting and Clinical Psychology, 60, 904-908.)

Compas, B. E., Haaga, D. A. F., Keefe, F. J., Leitenberg, H. \& Williams, D. A. (1998). Sampling of empirically supported psychological treatments from health psychology: Smoking, chronic pain, cancer, and bulimia nervosa.( Journal of Consulting and Clinical Psychology, 66, 89-112.)

DeRubeis, R. J. \& Crits-Christoph, P. (1998). Empirically supported individual and group psychological treatments for adult mental disorders.( Journal of Consulting and Clinical Psychology, 66, 37-52.) Drozd, J. F. \& Goldfried, M. R. (1996). A critical evaluation of the state-of-the-art in psychotherapy outcome research.( Psychotherapy, 33, 171-180.)

Elkin, I., Parloff, M. B., Hadley, S. W. \& Autry, J. H. (1985). NIMH Treatment of Depression Collaborative Research Program: Background and research plan.( Archives of General Psychiatry, 42, 305-316.)

Fensterheim, H. \& Raw, S. D. (1996). Psychotherapy research is not psychotherapy practice.( Clinical Psychology: Science and Practice, 3, 168-171.)

Fisher, R. A. (1947). The design of experiments (4th ed.).(New York: Hafner)

Frances, A., Kahn, D. A., Carpenter, D., Ross, R. \& Docherty, J. P. (1996). The expert consensus practice guideline project: A new method of establishing best practice.( Journal of Practical Psychiatry and Behavioral Health, 2, 295-306.)

Garfield, S. L. (1996). Some problems associated with "validated" forms of psychotherapy.( Clinical Psychology: Science and Practice, 3, 218-229.)

Goldfried, M. R. \& Padawer, W. (1982). Current status and future directions in psychotherapy.(In M. R. Goldfried (Ed.), Converging themes in psychotherapy: Trends in psychodynamic, humanistic, and behavioral practice (pp. 3-49). New York: Springer.)

Goldfried, M. R. \& Wolfe, B. E. (1996). Psychotherapy practice and research: Repairing a strained allience.( American Psychologist, 51, 1007-1016.)

Hayes, S. C. (1981). Single-case experimental design and empirical clinical practice.( Journal of Consulting and Clinical Psychology, 49, 193-211.)

Henry, W. P., Strupp, H. H., Butler, S. F., Schacht, T. E. \& Binder, J. L. (1993). Effects of training in time-limited dynamic psychotherapy: Changes in therapist behavior.( Journal of Consulting and Clinical Psychology, 61, 434—440.)

Hoagwood, K., Hibbs, E., Brent, D. \& Jensen, P. (1995). Introduction to the special section: Efficacy and effectiveness in studies of child and adolescent psychotherapy.( Journal of Consulting and Clinical Psychology, 63, 683-687.)

Howard, K. I., Moras, K., Brill, P. L., Martinovich, Z. \& Lutz, W. (1996). Evaluation of psychotherapy: Efficacy, effectiveness, and patient progress.( American Psychologist, 51, 1059-1064.)

Jones, E. E. (1993). Introduction to special section: Single-case research in psychotherapy.( Journal of Consulting and Clinical Psychology, 61, 371-372.)

Kazdin, A. E. (1981). Drawing valid inferences from case studies.( Journal of Consulting and Clinical Psychology, 49, 183-192.)

Kazdin, A. E. \& Weisz, J. R. (1998). Identifying and developing empirically supported child and adolescent treatments.( Journal of Consulting and Clinical Psychology, 66, 19-36.)

Kendall, P. C. \& Hollon, S. D. (1983). Calibrating the quality of therapy: Collaborative archiving of tape 
samples from therapy outcome trials.( Cognitive Therapy and Research, 7, 199-204.)

Lehrer, A. (1981, December). Not a science.( APA Monitor p. 42.)

Mental health: Does therapy help? (1995, November). Consumer Reports, 60, 734-739.

Millon, T. (1991). Classification in psychopathology: Rationale, alternatives, and standards.( Journal of Abnormal Psychology, 100, 245-261.)

Norcross, J. C. (1994). Prescriptive eclectic therapy [video].(Washington, DC: American Psychological Association)

Norcross, J. C. \& Beutler, L. E. (1997). Determining the therapeutic relationship of choice in brief therapy.(In J. N. Butcher (Ed.), Personality assessment in managed health care (pp. 42-60). New York: Oxford University Press.)

Norcross, J. C. (Ed.) \& Goldfried, M. R. (Ed.) (1992). Handbook of psychotherapy integration. (New York: Basic Books)

Parloff, M. B. (1979). Can psychotherapy research guide the policymaker?(A little knowledge may be a dangerous thing. American Psychologist, 34, 296-306.)

Persons, J. \& Silberschatz, G. (1998). Are results of randomized controlled trials useful to psychotherapists?( Journal of Consulting and Clinical Psychology, 66, 125-135.)

Prochaska, J. O. \& DiClemente, C. C. (1992). The transtheoretical approach.(In J. C. Norcross \& M. R. Goldfried (Eds.), Handbook of psychotherapy integration (pp. 300-334). New York: Basic Books.) Safran, J. D. \& Muran, J. C. (1995). Resolving therapeutic alliance ruptures: Diversity and integration.( In Session: Psychotherapy in Practice, 1, 81-92.)

Seligman, M. E. P. (1995). The effectiveness of psychotherapy: The Consumer Reports study.( American Psychologist, 50, 965-974.)

Snyder, W. U. (1950). Clinical methods: Psychotherapy.( Annual Review of Psychology, 1, 221-234.) Sobell, L. (1996). Bridging the gap between science and practice: The challange before us.( Behavior Therapy, 27, 297-320.)

Stricker, G. (Ed.) \& Gold, J. R. (Ed.) (1993). Comprehensive handbook of psychotherapy integration. (New York: Plenum)

Strupp, H. H. \& Anderson, T. (1997). On the limitations of therapy manuals.( Clinical Psychology: Science and Practice, 4, 76-82.)

Strupp, H. H. (Ed.), Horowitz, L. (Ed.) \& Lambert, M. J. (Ed.) (1997). Measuring patient changes in mood, anxiety and personality disorders: Toward a core battery. (Washington, DC: American Psychological Association)

Task Force on Promotion and Dissemination of Psychological Procedures (1995). Training in and dissemination of empirically validated psychological treatment: Report and recommendations.( The Clinical Psychologist, 28, 3-23.)

Wiens, A. N., Brazil, P. J., Fuller, K. H. \& Solomon, S. E. (1995). The practitioner's new weapon: Data.( Psychotherapy Bulletin, 30, 46-53.)

Wolfe, B. E. \& Goldfried, M. R. (1988). Research on psychotherapy integration: Recommendations and conclusions from an NIMH workshop.( Journal of Consulting and Clinical Psychology, 56, 448 - 451.) 
Further information regarding In Session: Psychotherapy in Practice may be obtained from Marvin R. Goldfried. 